\title{
Modernidad colonial, mito irracional y modernidades otras en América Latina*
}

\author{
Colonial Modernity, Irrational Myth and Other \\ Modernities in Latin America \\ Modernidade colonial, mito irracional e outras \\ modernidades na América Latina
}

Dra. María Cecilia Sánchez ${ }^{* *}$

\begin{abstract}
RESUMEN
Este artículo examina los diferentes significados de las concepciones europeas, norteamericanas y latinoamericanas sobre la modernidad. La hipótesis que se desarrolla es la aparición de una modernidad otra en América Latina, desde cuya discontinuidad resulta invalidado el binarismo entre aplicadores periféricos y creadores de centro, introduciendo una tensión entre el contexto local y la cultura denominada "universal" desde la colonialidad o "punto cero". Esta discusión se enmarca en el debate sobre modernidad y posmodernidad, abierto en los años cincuenta tras la Segunda Guerra Mundial. A partir de este periodo se pone en evidencia la delimitación entre una modernidad técnica americana y otra de corte cultural, moral y crítica en América Latina. Como parte de una modernidad otra debe considerarse la puesta en cuestión de la universalidad como colonialidad y la valorización de la transmodernidad; la reconsideración de la alteridad; la concepción del barroco como resistencia; la protesta como cons-
\end{abstract} Palabras clave: modernidad, colonialidad, alteridad, barroco, crítica

Este artículo forma parte de la investigación FIIC, 2018: "La modernidad, las modernidades y sus puntos de fuga en América Latina”, Folio 2017-2-11, Universidad Academia de Humanismo Cristiano. También forma parte del proyecto "Examen ético-político sobre la modernidad y el problema del Otro en América Latina", Fondecyt $\mathrm{N}^{\circ} 1200231$.

* Chilena. Licenciada en Filosofía por la Universidad de Chile, Diplome d'Études Aproffondies (DEA), doctora en Filosofía por la Universidad Paris 8, Saint Denis (Francia) y doctora en Literatura por la Pontificia Universidad Católica de Chile (cotutela). Académica y coordinadora de la Licenciatura en Filosofía del Instituto de Humanidades de la Universidad Academia de Humanismo Cristiano. Contacto: cecisanchez0@gmail.com ORCID: https://orcid.org/0000-0002-9543-9264 
trucción de un nosotros moral y las geopolíticas como formas de localización y enunciación de las modernidades.

\begin{abstract}
This article examines the different meanings of European, North American and Latin American conceptions on modernity. The hypothesis developed is that the appearance of an other modernity in Latin America, whose discontinuity invalidates the binary between peripheral appliers and central creators, introducing a tension between the local context and culture denominated "universal" from coloniality or "point zero." This discussion is framed within the debate on modernity and post-modernity, which opened up in the 1950s after WWII. From then on, we can see a delimitation between American technical modernity and the cultural, moral and critical modernity in Latin America. As a part of an other modernity, the questioning of universality as coloniality and the valuation of transmodernity must be considered, as well as the reconsideration of otherness, the conception of Baroque as resistance, protest as a construction of a moral we and geopolitics as forms of localization and enunciation of modernities.
\end{abstract}

\section{RESUMO}

Este artigo examina os diferentes significados das concepções europeias, norte-americanas e latino-americanas sobre a modernidade. A hipótese desenvolvida é a aparição de outra modernidade na América Latina, de cuja descontinuidade resulta invalidado o binarismo entre aplicadores periféricos e criadores de centro, introduzindo uma tensão entre o contexto local e a cultura denominada "universal" desde a colonialidade ou "ponto zero". Esta discussão se enquadra dentro do debate sobre modernidade e pós-modernidade, aberto nos anos 50 após a Segunda Guerra Mundial. A partir deste período fica evidente a delimitação entre uma modernidade técnica americana e outra de corte cultural, moral e crítico na América Latina. Como parte de outra modernidade se deve considerar o questionamento da universalidade como colonialidade e a valorização da transmodernidade; a reconsideração da alteridade; a concepção do barroco como resistência; a protesta como construção de um nós moral e as geopolíticas como formas de localização e enunciação das modernidades.
Keywords: modernity, coloniality, otherness, Baroque, critique

Palavras-chave: modernidade, colonialidade, alteridade, barroco, crítica 


\section{Introducción}

Abordar los comentarios a favor o en contra de la modernidad y la posmodernidad, ya sea europea (Heidegger, Arendt, Habermas, Vattimo, Lyotard), canadiense-americana (Taylor) y latinoamericana (Dussel, Roig, Castro-Gómez, Echeverría, Mignolo, Quijano), supone ingresar en una escena problemática, debido a que sus significados varían según las localizaciones y temporalidades desde los que se enuncian. Esta escena es problemática, porque pone en juego una noción de universalidad que debe dejarse atravesar por formas culturales en sus modos de intercambio y de traducción. En primer lugar, supone reconocer la situación colonial de ciertos discursos universalistas que carecen de lugares de enunciación. La hipótesis que me interesa desarrollar conjetura que la modernidad se resignifica permanentemente como concepto y como praxis en América Latina, especialmente en la segunda mitad del siglo XX, a propósito del debate con la así llamada "posmodernidad" en el contexto de la globalización. Asumir los significados inestables de la modernidad en América Latina y la problematización de su supuesto universalismo supone hablar de una "modernidad otra" (Echeverría), que discute la jerarquía entre "aplicadores" periféricos y "creadores" del centro.

En el siglo XIX, América Latina se había entendido como una "extensión" de Europa, cuya tarea consistía en la aplicación fiel de sus ideas y esquemas de pensamiento para alcanzar una mayoría de edad o madurez. De esta lógica ilustrada derivan las percepciones decimonónicas de Juan Bautista Alberdi, para quien, como nos hace saber Augusto Salazar Bondy, "la América práctica lo que piensa Europa" (Salazar Bondy 47). Igual que Alberdi, Andrés Bello concibe a los intelectuales y a las universidades de América Latina desde la aplicación de las concepciones racionales originadas en Europa. Sin embargo, esta lógica, cuya temporalidad es lineal y unidireccional, se arruina completamente si se asume la óptica del barroco latinoamericano. $\mathrm{Cu}$ riosamente, desde la modernidad europea el Nuevo Mundo fue pensado como el "futuro" de Europa (Quijano) o el "sueño" de un orden (Rama, 2004).

Con Irlemar Chiampi, Bolívar Echeverría y luego con la aparición del pastiche posmoderno mencionado por Frederic Jameson (1998), con relación a la modificación del capitalismo y la aparición de una 
nueva división global del trabajo, se habla de una desviación del proyecto civilizatorio de la modernidad. La modernidad se entiende de otro modo, pues se encuentra habitada por discontinuidades que la reconfiguran, recombinan y re-escenifican la voluntad unitaria del progreso lineal del mundo moderno. Desde la versión ibérica y latinoamericana del barroco, José Lezama Lima es uno de los primeros en proponer como paradigma de lo americano latino una suerte de "poiesis demoniaca". A diferencia del barroco europeo, acumulador de signos y significados, el americano "combina" de modo transcultural los fragmentos culturales que lo habitan (Lezama Lima). Muy lejos de la versión de Pedro Morandé del barroco escolástico, el barroco de América Latina contiene una política subterránea, subrayada por Chiampi a partir de Lezama Lima, suerte de "modernidad otra" (Echeverría) o "modernidad permanente" (Chiampi), que pone en tensión el contexto con lo que llegó a entenderse por cultura universal.

\section{La concepción europea de la modernidad en Heidegger y Arendt}

Para aproximarme a las claves filosóficas de lo que de modo intraeuropeo se ha entendido por modernidad, atiendo en primer lugar al pensamiento de Martin Heidegger y, luego, al de Hannah Arendt sobre el subjetivismo moderno. Para hablar de la modernidad, Heidegger establece como primera clave la nueva estrategia de investigación de la ciencia a partir del pensamiento de Descartes, incluida las ciencias de la historia, como denomina Heidegger a la investigación e interpretación de las fuentes cuya meta es representar lo constante para convertir la historia en un objeto entendido como "imagen del mundo". Con la palabra "imagen" entiende que el ser humano se convierte en "subjectum" o centro de referencia sobre la base de la representabilidad de lo ente, a diferencia de la Edad Media en la que lo ente es "ens creatum" (Heidegger 73-74).

Complementando a Heidegger y su lectura de Descartes, Arendt examina la Edad Moderna a partir de la perspectiva del cogito universal, movilizado por un tipo de duda que suspende cualquier modo de evidencia. Hasta ese momento, la concepción tradicional de la verdad suponía que ésta se podía revelar o que los humanos tenían las 
capacidades para captarla. Por el contrario, para Descartes este tipo de revelación es dudosa; ya no se puede confiar ni en los sentidos ni en la razón. Con esta desconfianza, Descartes parece conducirnos al escepticismo más absoluto, aunque nos salva a partir de la certidumbre en un cogito guiado por la certeza de su conciencia o mente. Con todo, lo que la mente encuentra en sus procesos introspectivos son solo los objetos de su conciencia, es decir, objetos ideales producidos por su mente (Arendt 301-306). Habría que destacar un problema en estas definiciones, ya que ni Heidegger ni Arendt se detienen demasiado en una filosofía de la reflexión o relación del sujeto consigo mismo, parámetro desarrollado por Kant. Tampoco se pronuncian sobre aquellos postulados de Hegel, desde una filosofía que busca superar la filosofía del sujeto, en la medida en que pretende abordar la simple relación de lo finito y lo infinito de la razón moderna desde el proceso que absorbe todo lo finito, cuyo remate en política y economía es la superación de la sociedad civil en el Estado. Este último aspecto, como se podrá apreciar, forma parte de lo que Dussel entiende por "mito irracional de la modernidad", ideología colonialista que podría superarse mediante la "trans-modernidad", cuya virtud ética es considerar la razón del "otro" negada por la modernidad colonizadora (Dussel 1992 208-2010).

Así esbozados algunos de los significados europeos de la modernidad, el cometido es examinar las perspectivas latinoamericanas sobre la o las modernidades alternativas (Dussel, Roig, Castro-Gómez) o modernidades “otras” (Echeverría). La exposición de las perspectivas de los autores mencionados más arriba se hace explicitando las concordancias, tensiones y debates con algunas de las reflexiones europeas, norteamericanas y canadienses sobre la modernidad y la así llamada "posmodernidad".

\section{Modernidad y colonialidad: lo "otro" de la razón}

¿Por qué asumir la locación de América Latina para discutir sobre la modernidad? En primer lugar, porque la existencia del así llamado "Nuevo Mundo" ha dependido de un tipo de mirada y de racionalidad que en el siglo XX pasa a estar cuestionada con mayor firmeza que en épocas anteriores; me refiero a la mirada objetivante de una razón calculadora, encubierta en la idea del progreso como historia 
única, que Walter Mignolo denomina su "retórica" (7). En "La época de la imagen del mundo", texto recientemente citado, Heidegger señala un aspecto fundamental del subjetivismo moderno y de su metafísica al entender que el fenómeno de la Edad Moderna es la conquista del mundo como "imagen", queriendo decir que esta forma de representación es la "posición" que pone en juego el poder ilimitado del cálculo y la planificación de todas las cosas, incluida la aniquilación de las grandes distancias y el predominio de lo "gigantesco", que hace que lo cuantitativo se convierta en la cualidad propia de todas las cosas (Heidegger 77-78).

Por su parte, Arendt le atribuye al subjetivismo moderno el poder de suprimir el pensamiento político y el espacio público, poniendo en su lugar el modelo del hombre productor preocupado del "cómo" procesual o del "desarrollo", cuyo efecto más temido es el totalitarismo. Desde América Latina, Santiago Castro-Gómez describe la apropiación moderna de la que es objeto el así llamado "Nuevo Mundo", mediante categorías como lo "liso" y lo "estriado", ambas tomadas de Mil mesetas, de Gilles Deleuze y Félix Guattari. Así, por ejemplo, la conversión del Atlántico en un territorio que regula la circulación de mercancías, de esclavos y personas entre el Nuevo y el Viejo Mundo por parte del imperio español es una forma de "estriar el mar", de modo semejante a como se mapea el espacio terrestre y su población (Castro-Gómez 2010 247-248). Como categoría epistemológica, la colonialidad a la que se aproxima Castro-Gómez tiene relación con un tipo de mirada muy bien ilustrada por la geografía, que entiende los recursos naturales únicamente desde la perspectiva de su utilidad económica. De este modo, el "punto cero" al que se refiere este autor parece ser equivalente a la "posición" del subjetivismo de la que habla Heidegger, solo que esta vez es el punto de mira del colonialismo europeo. Siguiendo a Aníbal Quijano, Walter Mignolo es tajante al respecto: "No hay modernidad sin colonialidad" (Mignolo 47), de allí que proponga como alternativa la descolonización del saber y del ser (48).

Antes de aproximarme al colonialismo, vale la pena reparar en el punto de vista asumido por Jürgen Habermas en su El discurso filosófico de la modernidad, libro en el que repasa los discursos del racionalismo moderno y de los críticos de la razón, asumiendo en parte algunos de los argumentos de los críticos de Hegel del periodo ro- 
mántico y la crítica de Heidegger sobre la racionalidad con arreglo a fines, aunque sin renegar, como Heidegger, de la capacidad crítica de la modernidad. Pese a que Dussel y Mignolo ven en el pensamiento de Habermas una voluntad invisibilizadora del lado más "oscuro" de la modernidad, esto es, el de la colonialidad, Habermas reconoce el problema provocado por la razón. En vez del paradigma de la conciencia, que engulle de modo totalizante lo otro de la razón, propone el paradigma del entendimiento intersubjetivo, con participantes lingüísticamente mediados y diferenciados en su actitud del sujeto objetivante de las entidades que le salen al paso. Este paradigma, que lleva la marca de Apel y de Habermas, puede reconocerse en Dussel, en la medida en que entiende la transmodernidad desde una relación dialógica entre culturas.

Lo otro de la razón es precisamente el problema que aborda Enrique Dussel en su libro sobre el encubrimiento del Otro (1992), para quien el nacimiento del Nuevo Mundo se enlaza con el significado cultural de la modernidad en su sentido ético-político, ya que 1492 es la fecha en que "Europa pudo confrontarse con 'el Otro' que Europa" (Dussel 1992 10). Esta confrontación es la que da curso al nacimiento del "ego", en el caso de Europa, y de la "alteridad", en el caso del Nuevo Mundo. Otras fechas destacadas por Dussel son, respectivamente, 1511 y 1514, por generarse las primeras críticas al colonialismo que, según Dussel, inauguran una modernidad bastante anterior a la de los discursos cartesianos. Por contraste a los filósofos modernos "de centro", como Descartes, Kant y Hegel, para Dussel el primer crítico de la modernidad es Bartolomé de las Casas, quien, en el contexto de la apertura del mundo europeo al Atlántico, siendo español, asume la responsabilidad por el Otro al defender en Valladolid a los indígenas de la esclavitud y de la colonización española, en confrontación con los argumentos aristotélico-tomistas de Juan Ginés de Sepúlveda (Dussel 2007). De las Casas acepta el disenso con el Otro, otorgándole validez a sus razones, refutando la superioridad de la cultura occidental, pero, sobre todo, descubriendo que los habitantes del Nuevo Mundo son el "Otro de la modernidad naciente" (Dussel 2018 193). En el marco de lo que puede entenderse por filosofía política, el pensamiento de Las Casas es anterior al de filósofos reconocidamente modernos, como Hobbes, Spinoza y Locke. Este periodo es descrito por Dussel como el de la modernidad temprana, anterior al "mito 
de la Modernidad europea", que posteriormente ejercerá un derecho universal sobre las colonias y el globo terráqueo en general. En este sentido, Dussel consagra al discurso de Bartolomé de las Casas como el "primer anti-discurso de la Modernidad" (2018 202), siendo este mismo discurso moderno "primero" con relación al de Descartes, a quien sitúa como el segundo momento de la modernidad temprana. En este punto, es importante indicar una distinción sobre la noción de "modernidad" introducida por Dussel en varios de sus textos. Por una parte, a los filósofos que entienden que la modernidad deriva solo de Europa los tilda de "eurocéntricos", mientras que a quienes la entienden en relación con una periferia, la modernidad se les aparece como el "centro de un proceso mundial". Este "centro" se confronta con una periferia colonial, primero, y neocolonial, después, cambiando esta denominación a "Tercer mundo" y "subdesarrollo estructural" en la época de la Guerra Fría (Dussel 1998 113). La noción de "mundialidad", usada por Dussel en lugar de "universalidad" supone que la modernidad involucra a todas las culturas del planeta, pues aparecen como formas de alteridad dominadas o antagónicas. Para este autor, es importante situarse en la exterioridad o alteridad del principio de lo moderno para poder caracterizar sus contradiscursos. De hecho, caracteriza de "contradiscurso" de la modernidad y de la posmodernidad a su Filosofía de la Liberación, en la medida en que es una filosofía crítica que nace de la periferia y tiene pretensión de mundialidad (1998 118-119).

Saliendo de Dussel, habría que reconocer a Habermas el dar cuenta del principio inmanente de la modernidad que la hace entrar en conflicto consigo misma. Para Quijano, uno de los ejes de diferenciación social de la modernidad es la "raza", entendida como construcción mental que expresa la experiencia de la dominación social. "Indios", "negros" y "mestizos", contrapuestos al "portugués" y el "español”, cuyas identidades geográficas devienen europeas, además de adquirir una connotación racial. Así, lo fenotípicamente clasificado obtiene sentidos jeraquizantes que propician la esclavitud y luego la servidumbre, tema ya advertido por José Martí y José Carlos Mariátegui, entre otros.

En su preocupación por el "Otro", Dussel hace patente su vínculo con la filosofía política de Lévinas, en especial con su crítica a la "Tota- 
lidad", aunque reniega de la negatividad que vuelve imposible una arquitectónica positiva que pueda mediar en favor del Otro ${ }^{1}$. En la defensa del Otro también debe resaltarse su diálogo y diferenciación con la Escuela de Frankfurt, pues, desde una lectura no eurocéntrica, reconoce el locus de enunciación de la víctima asediada por el autoritarismo, el machismo, el capitalismo y/o el colonialismo. En su favor, considera que su mirada crítica aporta una ampliación de lo que se entiende por "violencia" y por "víctima", ya que, en dicha escuela, solo se consideran víctimas al obrero y al judío. Por lo mismo, postula una filosofía crítica con validez mundial, que permita variados lugares de enunciación y de diálogos de comunicación horizontal.

\section{Modernidades no europeas o euroamericanas}

En este primer paisaje o esbozo acerca de las diputas sobre la modernidad europea y latinoamericana, quise mostrar el primer lazo entre la modernidad europea y la creación/negación del Nuevo Mundo desde la óptica de Dussel y Quijano. Veamos ahora qué se entiende por modernidades no europeas.

No se debe olvidar que, en un nivel histórico, hay varias modernidades europeas. Richard Morse contabiliza al menos cuatro: la británica, la ibérica, la francesa y la alemana, aunque a esta última la considera una metafísica "compensatoria" y a la francesa la juzga de ser "demasiado elegante" (28). En cambio, Quijano prefiere hablar de una modernidad "euronorteamericana" (3). Bajo este nombre incluye el embate contra la modernidad de corrientes de mediados y fines del siglo XX, como el "posmodernismo", el "antimodernismo", el "neoliberalismo" o "neoconservantismo", sobre todo tras el fin de la guerra de Vietnam (4).

Fuera de Europa, la versión norteamericana de la modernidad sobresale por su "pureza", pues carece de resistencia si se la compara con la europea que entra en conflicto con formas de vida premodernas, según señala Bolívar Echeverría (2011) a propósito de la trayectoria casi

Es importante señalar la conexión entre Dussel y Heidegger, al punto que Arturo Andrés Roig llega a decir que Dussel es deudor de Heidegger, sobre todo en la concepción de una crisis del sujeto. Sin embargo, pudo superarlo gracias a la lectura de Lévinas (Roig 2002 30). 
rectilínea seguida por los colonos puritanos que, provenientes de la Europa noroccidental, la fundan en el siglo XVII en la América del Norte. Si se la coteja con la de Europa del sur del orbe mediterráneo, cuya geografía tiene un trasfondo cultural, pues se define por su catolicidad, la modernidad protestante o noroccidental es más dócil al capitalismo. Echeverría se sirve de Max Weber para decir que el perfil del hombre norteamericano tiene una ética funcional al espíritu del capital en la clave del "American way of life" (Echeverría, 201126$).$

Respecto de la caracterización que Charles Taylor hace de lo moderno, Dussel le reprocha un eurocentrismo de corte helenocéntrico, ya que, siendo un lector canadiense, su punto de partida para la reconstitución de la modernidad y de las fuentes del yo (Self) es Platón y su idea de "Bien" (agathón). Desde el punto de vista de Dussel, más útil le hubiese resultado a Taylor el dios Osiris de los egipcios, cuyos principios éticos contienen algún tipo de alteridad, no así los criterios platónicos. La crítica a Taylor es terminante, porque desde su eurocentrismo se deriva una reflexión sobre la modernidad autocentrada y no dialéctica. Además, con su concepción de la autenticidad en el mundo de la vida, cuya fuente es un ethos concreto que toma prestado de la ontología heideggeriana, Dussel le reprocha que no es consciente de los Otros a los que determinadas culturas niegan. De este modo, el "bien" de una cultura determinada no puede ser el fundamento de la moralidad. En este sentido, el comunitarismo de Taylor sería relativista, de acuerdo con el juicio de Dussel.

¿Qué ocurre con América Latina, cuya herencia es la cultura ibérica? Desde el punto de vista de Leopoldo Zea, los pueblos al sur de los colonizados por los anglosajones aparecen más inclinados al "trabajo estético", a la "contemplación" y a las "abstracciones" de carácter metafísico o religioso. Tales preferencias se deberían a la herencia de la cultura íbera, debido a que significan el trabajo material como instrumento para acciones más altas. De ahí que la riqueza se aprecia en la medida en que está puesta al servicio de la personalidad. A diferencia de la concepción del anglosajón, la riqueza ibérica es "acumulación inútil" orientada a la "exhibición y derroche" (75). Esta es la razón, según Zea, para "no esforzarse en inventar instrumentos que permitiesen producir más de lo que necesitaban" (76). Contrariamente a la dignidad que tiene el trabajo en la cultura anglosajona, "en las zonas 
ibéricas se privilegian los grandes hombres, emperadores, capitanes, conquistadores y santos" (76).

Desde la óptica calvinista del trabajo, "la hybris americana", según la denomina Echeverría (2011), es la desmesura de una completa "artificialización de lo natural” (30), bajo una planificación y un diseño eficiente, al estilo de una "coreografía laboral", según la llama, anticipando el exceso en juego con la detonación de la bomba atómica en 1945, que pone fin a la Segunda Guerra Mundial y a la modernidad, al menos tal como se la había entendido. Ya a finales del siglo XIX, Rubén Darío y José Enrique Rodó destacan por su crítica a la cultura utilitarista procedente de los Estados Unidos, especialmente cuando, bajo la doctrina Monroe, la América sajona comienza a absorber a la América iberoamericana, que opta por adjetivarse de latina. Darío escribe en una elocuente crónica titulada "El triunfo del Calibán" (1889), que los "yankees" quieren "tragarse" con sus "tentáculos de ferrocarriles" y "bocas absorbentes" a la "raza latina". Bajo estos términos, la latinidad impugna al materialismo vulgar de la América sajona (Sánchez 247).

\section{Posmodernidad, hermenéutica, transmodernidad}

Para aproximarse al debate latinoamericano y norteamericano sobre la modernidad, es necesario situarse en los años 50, tras la Segunda Guerra Mundial, para ver la línea divisoria entre la modernidad y la así llamada "post" o "posmodernidad". Este debate presenta la perspectiva de modernidades no europeas que, además de América Latina y Estados Unidos, incorpora a Rusia, Turquía y China. Como señala Perry Anderson, a partir de A. Tonybee, la perspectiva de una modernidad no europea es renombrada por este último autor como "post-modern age". Según Anderson, este término se difunde en Norteamérica, primero bajo el empleo de Charles Olson para caracterizar, en su correspondencia con el poeta Robert Creerley, el presente como "post-moderno", "post-humanista" y "post-histórico", debido a las explosiones atómicas, lo que caracteriza como un acto "terrorista nuclear" que representa el cierre de la edad moderna (Anderson 14). Esta calificación es muy similar a la sostenida por Hannah Arendt en La condición humana, quien, en su Prólogo, señala que la Edad Moderna termina con las explosiones atómicas en el siglo XX, momento en que adviene el "Mundo Moderno", dividiendo de modo decisivo el conocimiento técnico que 
fabrica artefactos, del pensamiento político (Arendt 16-18). De modo muy escueto, puede decirse que en este periodo se evidencia más que nunca que la modernidad se escinde entre una razón instrumental y una razón moral o crítica como componentes de lo político, según se verá. Autores como Zea, Dussel, Roig y Echeverría reconocen en su pensamiento la crisis que vive la modernidad europea. Por lo mismo, validan la experiencia periférica de la occidentalización. En el caso de Castro-Gómez, su apreciación positiva hacia la posmodernidad es mayor, incorporando una fuerte crítica a los ideales del humanismo moderno y a los de la historia como vehículo de esos ideales, reconociendo a su vez en Ángel Rama y en Walter Mignolo una narrativa que no se construye en el nivel de las conciencias, sino en marcos epistemológicos y relaciones de fuerza con efectos de verdad (Castro-Gómez 1996 115).

\section{Dussel y Roig en disputa con Vattimo y Lyotard: transmodernidad, protesta moral y discurso del futuro}

Desde el punto de vista de la posmodernidad, Enrique Dussel entabla un diálogo con Gianni Vattimo en 1993, en un seminario organizado en la Universidad Iztapalapa, de Ciudad de México. Vattimo es un conocido filósofo italiano que da cuenta del "fin de la modernidad", haciéndose cargo de la crisis del humanismo que había puesto al hombre como "centro", según la denuncia de Heidegger tras la Segunda Guerra Mundial en su "Carta sobre el humanismo" (Vattimo 34). En comparación con Vattimo y su propuesta de una hermenéutica que arranca de los postulados nihilistas y estéticos de Heidegger y Nietzsche como falta de unidad y des-fundamento, Dussel define su postura como una ética, porque habla desde una filosofía de la liberación que parte "desde el Otro como pobre, como mujer dominada eróticamente, como raza discriminada, como juventud o pueblo cultural y pedagógicamente dominado..." (Dussel 1998 160). Desde el lado del pensamiento de Vattimo, la consigna es "el fin" de la modernidad, en concordancia con el "fin del metarrelato que implica una filosofía de la historia" (Lyotard 9). Precisamente, para Vattimo, este "fin" es nada menos que el de la "la historia como realización progresiva de la humanidad auténtica", además de la finalización del despliegue de este proceso como "unitario". Es importante subrayar el proceso unitario de la "Modernidad", escrita 
con mayúscula, porque, a juicio de Dussel, esta versión de la historia moderna suponía un "centro": Europa, y unas "periferias": América, Asia y África (Dussel 1992 206). Dussel reprocha a Vattimo no tener conciencia de la regionalidad y del "provincianismo" de los fenómenos anteriores a 1492. Así, para el autor argentino, Aristóteles, Maimónides o Tomás de Aquino serían "pensadores regionales", a diferencia de Bartolomé de las Casas, Descartes o Kant, que serían pensadores de "centro". A Dussel le importa dejar en claro que la centralidad europea se vuelve "mundial" solo a partir de los viajes y la dominación española y portuguesa. Con esta demarcación, Dussel busca demostrar que a Vattimo, Habermas, Taylor y a muchos otros les falta considerar la modernidad que se desarrolla como una dialéctica entre el centro y la periferia. En consecuencia, el pensamiento del filósofo italiano también sería eurocéntrico, pues no advierte que tanto en el origen como en el fin de la modernidad cuenta la periferia. Por esta vía establece que no hay modernidad sin "modernizado", así como no hay civilización sin "bárbaro". Este es el planteamiento que Dussel caracteriza como "Mito de la modernidad" (1998 161). Para Vattimo, en cambio, la violencia de la Modernidad como ratio "estratégico-instrumental" no se relaciona con la aniquilación de culturas no europeas pertenecientes a un amplio mundo colonizado. Es por este motivo que el planteamiento de la "razón débil" de la posmodernidad no le basta a Dussel. Para este autor, es necesario establecer una "razón liberadora”, una ética" que reconozca la dignidad de la "alteridad negada" (162). Sobre la base de este diálogo, Dussel asume lo recuperable de la Modernidad, llamando a esta recuperación “Transmodernidad” (162), porque recoge la dignidad de los afectados por la Modernidad. En todo caso, es apreciable una concordancia con Vattimo en cuanto a reconocer el momento final de la Modernidad, pese a descartar su propuesta de un "irracionalismo moderado". En especial, porque a Dussel le importa desarrollar las potencialidades alternativas de quienes han sido la "exterioridad" de la Modernidad. Para Vattimo, situarse en una racionalidad moderada supone relacionarse con una "hermenéutica" o "pensamiento débil”, apartándose de la racionalidad epistemológica o "ciencia normal”, según la caracteriza Thomas Khun. Dussel aprueba las críticas, tanto de Vattimo como de Lévinas, respecto del racionalismo epistemológico y la exigencia de concordancia y de transparencia del lenguaje del discurso racional, en el que coinciden el aspecto instrumental, el eco- 
nómico y el militar. Lévinas denomina "racionalismo del terror" a este discurso, advirtiendo que es tan peligroso en el ámbito de la medicina como en el del Estado, ya que, cuando alguien no sigue esta lógica de la razón, puede llegar a ser encerrado en una prisión, en un psiquiátrico o capturado por los servicios de inteligencia.

La incomodidad de Dussel con el irracionalismo moderado de Vattimo se debe también a que su pensamiento no tiene espacio para el Otro antropológico (167). En respuesta a Vattimo propone una "razónético-originaria", única forma de ser responsable por el Otro antes de toda deliberación. A diferencia de Vattimo, Lévinas es transontológico, sobrepasando el pensar ontológico atado a una situación inescapable como la del ser-ahí, en el caso de Heidegger. De todos modos, en el ámbito de la hermenéutica coincide con el pensamiento débil, pero solo en la medida en que la interpelación del Otro, de quien está afuera, se base en interpretaciones metafóricas y análogas antes que unívocas. A modo de ejemplo, Dussel sostiene que la Modernidad ha impuesto su texto a las culturas dominadas, a la vez que invisibiliza o "enfría" los textos de dichas culturas. Para el autor argentino, la Trasmodernidad, debido a su carácter planetario, es la alternativa a la postura que postula el fin de la Modernidad, porque de esa manera aparecería una civilización que realiza los valores de los de "afuera", esta vez como "justicia cultural" y como "recreación ecológica". Se puede advertir que Dussel se queda con una razón que contenga criterios éticos "supra regionales" y mediaciones institucionales que posibiliten su realización.

Arturo Andrés Roig es otro de los filósofos argentinos que entra en disputa con Vattimo y su pensiero debole (o pensamiento débil). En su caso, asume el aspecto normativo del pensamiento filosófico moderno como un "pensamiento fuerte" que está presente en América Latina (Roig 2002 108), aunque también se aleja de la dimensión lógico-epistemológica, cuestionada por varios pensadores europeos y latinoamericanos que participan en este debate. La dimensión lógico-epistemológica es la que está más ligada al pensamiento de Descartes; cognitividad metódica apropiada por las ciencias naturales, humanas y sociales. A la inversa del modo cognitivo y causal de la razón, Roig recurre a Kant y Hegel para desarrollar su perspectiva del ejercicio de la crítica y del tipo de sujeto moral que opera en América Latina, reconociendo el legado de la cultura europea, aunque bus- 
cando poner el acento en el discurso político de la filosofía. Primero trata del a priori kantiano en su libro Teoría y crítica del pensamiento latinoamericano (publicado en 1981 y reeditado en 2009), desarrollando como alternativa al a priori kantiano su planteamiento acerca del "a priori antropológico". Habría que señalar un aspecto histórico que acompaña al a priori recién mencionado y a la "filosofía de la liberación". Adriana Arpini nos remite a la Declaración de Morelia ${ }^{2}$, firmada en un coloquio en México, en la que Roig y Dussel señalan su compromiso de pensar la realidad de América Latina "con intención liberadora" (Arpini 343). En el caso de Roig, se trataba de vincular la filosofía con la facticidad como la situación de un pensar existencial vinculado con la experiencia. Bajo este tipo de a priori establece un diálogo con el a priori histórico desarrollado por Foucault, aunque se distancia del desplazamiento que el autor francés hace respecto del sujeto (Contardi 161-162). Roig finalmente se queda con el término "a priori antropológico" en vez de "histórico" (2009). Como señala Arpini, la "aprioridad" aludida desde el a priori histórico/antropológico apunta a la experiencia vital y la cotidianidad (346-348) que, como su par chileno, Humberto Giannini, se aparta de la apuesta de la filosofía academicista. También aporta con lo que Arpini denomina una "ampliación metodológica", al considerar un tipo de lectura simbólica y del discurso que toma de Vladimir Propp su capacidad para leer en lo narrativo lo político e ideológico. Asimismo, Roig toma de Hegel el conocerse por sí mismo en la medida en que el sujeto se tiene como "valioso", pese a increpar al filósofo alemán por borrar la moralidad del sujeto en pos de la eticidad institucional del Estado. Entiende que el sujeto crítico es un sujeto que se reconoce a sí mismo, aunque, en el caso de Roig, este sujeto es empírico y no lógico en cuanto a su temporalidad e historicidad. En todo caso, Roig considera que el "nosotros" referido a los "latinoamericanos" no es una objetividad identitaria, sino un "deber ser" proyectivo, resignificando la noción del sujeto trascendental a partir de la facticidad de una moral de la emergencia, ejercida desde la "sujetividad" o solidaridad en la esfera de la sociedad civil antes que de la "subjetividad" entendida como lugar de conflictividad (Roig 2002 31-40). Es

Esta Declaración es firmada por ambos filósofos argentinos en1975, además de Zea, Miro Quesada, entre otros. 
importante indicar que la sujetividad es una conducta inspirada en lo que Rousseau entiende por sociedad civil, hecha de rabia, utopías o neotopías (Roig 2002 46). También que, con la emergencia del sujeto moral, Roig se aleja de la ética del discurso, según es entendida por Habermas y Adela Cortina (108). El proceso histórico subrayado es partir de una moral teológica para pasar por lo que Bilbao llama el "Evangelio americano", hasta la moral sin dogmas descrita por José Ingenieros (111). Con este planteamiento, Roig supone un "hacerse" de la filosofía hecha de recomienzos, encontrando en América Latina un saber práctico-moral bastante alejado del ego cartesiano, cuyo conocimiento tiene un carácter causal y mecanicista. De esta autoconstitución deriva el reconocimiento del otro como sujeto. A partir de estos planteamientos, asume que la liberación o transformación, si bien no es filosófica, está presente en las bases de la filosofía. Recalca así que cada quien o cada comunidad puede sacar desde sí mismo formas de quehacer que, por lo general, se imitan o repiten. El énfasis en la filosofía es bastante aminorado en estos escritos, sin perder el soporte crítico que le interesa destacar a propósito del pensamiento y de la praxis social en autores latinoamericanos como Martí, Rodríguez, Hostos, Mariátegui, entre muchos otros.

Me atrevo a vincular el planteamiento de Roig con el principio de la subjetividad según la entiende Hegel, sin ser este un término filosófico, sino una práctica moderna de la sociedad civil que Roig entiende como "sujetividad". De modo resumido, se puede decir que el principio de la subjetividad en Hegel es opuesto al espíritu armónico del mundo griego que imita un orden natural con sus jerarquías y sujeciones. En su lectura de Hegel, Miguel Giusti indica que este principio representa la pérdida del sustancialismo en el que se fundaba la ética griega. A cambio, la subjetividad distingue al mundo moderno por el uso de la autonomía o autodeterminación de la razón, así se explica el surgimiento de la Reforma, la Ilustración, la Revolución Francesa, la sociedad civil y el arte moderno, puesto que se trata de autoproducirse desgarrando todo lo establecido (Giusti). Es importante aclarar que Hegel admira y teme a este principio, descrito más adelante por Castro-Gómez en diálogo con Zizek. En virtud de este miedo, en Principios de la filosofía del derecho Hegel vuelve a vincular el concepto de subjetividad (libertad) con el de sustancia (eticidad resustancializada) apostando por una institución como el Estado. 
Volviendo a la relación de Roig con la posmodernidad, es conveniente recordar el modo en que Castro-Gómez, pese a sus críticas a la filosofía de Roig como "filosofía de la historia" (1996), acoge el planteamiento del filósofo de Mendoza sobre la modernidad, a propósito de la toma de posición frente a la posmodernidad en América Latina. Sobre este aspecto, Castro-Gómez señala: "la posmodernidad no es lo que viene después de la modernidad, sino que es la asunción de la conciencia de crisis que caracteriza a la modernidad misma" (1996 32). Con relación a Roig, considera un pasaje de su libro titulado Rostro y filosofía en América Latina (212): "Arturo Andrés Roig lo ve muy claro esta vez al decir que "el posmodernismo sería el modo como en nuestros días la modernidad ejerce algo que siempre ejerció: la crítica"' (Ibíd.). Castro-Gómez reconoce también a Leopoldo Zea en esta línea, pues la posmodernidad es considerada la "modernidad de la modernidad" (Ibíd.).

$\mathrm{Al}$ revisar más de cerca el libro de Roig citado por Castro-Gómez, me refiero a Rostro y filosofía de Nuestra América (2011), descubro que allí la modernidad es caracterizada como un "discurso de futuro" y, en términos filosóficos, este discurso es defendido como una "filosofía del mañana". Esta es la respuesta definitiva que Roig entrega a Vattimo, quien pretende desembarazarse de este tipo de historicidad. A propósito de la historicidad defendida, Roig también discute con Lyotard y la muerte de los "metarrelatos", cuya lógica interna reúne "el relato de la especulación" con "el relato de la emancipación" (118). Como bien se sabe, los autores más célebres reconocidos por este tipo de narrativa sobre el "espíritu", el "pueblo" o la "humanidad" son Kant, Hegel y Marx. Por el contrario, el pensar posmoderno, queriendo criticar al discurso científico y su lenguaje descriptivo, se desembaraza de todos los discursos o relatos que apuestan por lo justo o injusto. Roig plantea muy bien la brecha abierta por Lyotard entre lo verdadero de ciertos leguajes narrativos, especialmente los de corte científico, y lo críticomoral, vehiculizado por lenguajes prescriptivo-políticos. En el caso de las ciencias, el diagnóstico de Lyotard establece que desde los años 50 este lenguaje deja de vincularse con el lenguaje de la moral para devenir "mercancía" o "valor de cambio". Lyotard establece sus juicios sobre la posmodernidad como "condición" a partir de los "juegos de lenguaje". Desde la operatividad de estos lenguajes, el relato de la verdad, que desde las Luces era el que sostenía la praxis de la emancipación, se 
transforma en "performatividad". Contrariamente a los postulados de Lyotard, desde un punto de vista moral, la filosofía latinoamericana o historia de las ideas es vista por Roig como un ejercicio que desarrolla un discurso prescriptivo o crítico, no descriptivo. Por lo tanto, la teoría de los metarrelatos, según la expone Lyotard, no afecta su ejercicio crítico ni su poder emancipador (119).

De este modo, Roig intenta defender para la filosofía latinoamericana un tipo de narración moderna del "deber ser", asociada a la matinalidad o "discurso de futuro" (121-122), como contrapunto a la filosofía del "atardecer", símbolo usado por Hegel para referirse a lo que ya ha sido. Para salvaguardar este sentido de lo "abierto" de la filosofía latinoamericana, Roig discute con Vattimo nuevamente debido a que ve en la "matinalidad", símbolo tomado del pensar nietzscheano, una "puerta de escape" respecto de la violencia de la metafísica moderna, a diferencia de Roig que ve en la simbólica de la "mañana" una forma de liberación.

\section{Castro-Gómez, Zizek y Dussel en debate: la recuperación del sujeto, el problema de la universalidad y la política instituyente}

Como penúltimo apunte sobre los problemáticos empalmes y desacoples entrelas concepciones dela modernidadylaposmodernidad europea, norteamericana y latinoamericana, examino algunos de los planteamientos de Castro-Gómez y sus críticas a filósofos como Arturo Andrés Roig y Enrique Dussel. Dentro de este examen, considero el cambio de opinión del autor colombiano sobre la modernidad a partir de su diálogo con Slavoj Zizek en Revoluciones sin sujeto (2015). Concluyo con algunos de los rasgos de lo que cabe entender por "modernidad otra", de acuerdo con el examen realizado por Bolívar Echeverría a propósito del ethos barroco en América Latina.

La apreciación de Castro-Gómez acerca del pensamiento posmoderno en América Latina es caracterizada primero como un "cambio de sensibilidad"; así lo expone en su Crítica de la razón latinoamericana (1996 22). Acompañado de autores como José Joaquín Brunner, Nelly Richard, Beatriz Sarlo, Daniel García Delgado, Martín Hopenhayn, entre otros, en este libro busca especificar que América Latina se ha apropiado de la modernidad y de su crisis de modo diferente a Europa 
o Estados Unidos (24). Con Daniel García Delgado, entiende que hemos pasado de una cultura "holística" a una "neoindividualista", con identidades restringidas y ya no colectivas. De Roberto Follari toma la constatación del "ablandamiento de las opiniones políticas", la tendencia a la inmediatez y el menor aprecio por las liberaciones integrales. Al leerlo pareciera que estas constataciones son, de algún modo, una suerte de repuesta a Roig, ya que la nueva sensibilidad posmoderna supone un abandono de las "utopías" y de cualquier "futuro posible". Para este autor, en sustitución de los ideales racionales de la política surgen los "espectáculos" y "escenografías" montados por los mass media (27), cuyos referentes son transnacionales. Esta última descripción la toma de José Joaquín Brunner, quien es hoy uno de los sociólogos cercanos al pensamiento neoliberal.

A partir de estas descripciones, Castro-Gómez sostiene que la posmodernidad es, ante todo, "un estado de ánimo" (30). Sobre todo, se demarca de un sentir neoliberal, recogiendo de Martín Hopenhayn la idea de que la posmodernidad es "apertura cultural", diferenciada de la que provenía del gigantismo del sector público (31). Desde el punto de vista europeo, en compañía de autores como Vattimo, Lyotard, Derrida y Foucault, Castro-Gómez confirma el "fin de la modernidad" y se deshace del paradigma de la Historia Universal, aunque, hay que decirlo, la filosofía latinoamericana también rechaza la caracterización unitaria de la Historia Universal, según se puede apreciar en Dussel, entre otros. Desde el punto de vista de América Latina, Castro-Gómez incluye en ese "fin" a la "teoría de la dependencia” y a las "filosofías de la liberación” (36).

Sin embargo, en el libro Revoluciones sin sujeto (2015) hay un cambio brusco en los planteamientos y valoraciones de Castro-Gómez sobre la posmodernidad y sobre el discurso moderno. Este libro es un diálogo con el conocido filósofo y psicoanalista esloveno Slavoj Zizek, crítico del historicismo posmoderno a partir de una lectura lacaniana del idealismo alemán y del sujeto trascendental. En este caso, el filósofo colombiano acepta varias de las críticas a la posmodernidad elaboradas por Zizek, aunque desarrolla comentarios críticos contra el eurocentrismo declarado de Zizek, contrastándolo con la filosofía política de Latinoamérica, en especial la de Ernesto Laclau y de Enrique Dussel. Asimismo, valida las luchas feministas, antirracistas y eco- 
logistas, considerando a Negri, Rancière, Butler, Badiou, entre otros, autores menospreciados por el filósofo esloveno.

Para comprender la postura de Castro-Gómez ante Zizek, debo desarrollar una larga cadena de argumentos que nos ponen ante el problema del universalismo, los significantes vacíos y la diferencia ontológica. Sobre la posibilidad de "abandonar la modernidad", establece nexos con su libro Crítica de la razón latinoamericana, indicando que defiende a la modernidad frente a las "epistemes-otras".

Parto situándome primero en los dardos enviados por Zizek a Foucault y Deleuze, quienes en mayo del 68 cambiaron, según el autor, un "amo" por "otro": se refiere a una profecía inicialmente señalada por Lacan cuando se reclama por mayor libertad sexual, contra la alienación cultural y socioeconómica, contra la sociedad de masas, entre otras. A su vez, esta profecía es constatada por Zizek por haber caído en las manos del "amo posmoderno" y en la circulación de las mercancías que llenan nuestras vidas de significado en el contexto de un capitalismo globalizado o, como también lo llama, "digitalizado" (15).

Cuando nombra a Deleuze, su crítica es a la "desterritorialización", al "nomadismo" y a las "máquinas deseantes". El pensamiento deleuziano es rotulado de "ideología de la nueva clase dominante emergente" (15), debido a que el nuevo capitalismo recupera la retórica igualitaria y antijerarquía del 68, pero en el ámbito empresarial o en la flexibilidad laboral, incluyendo al Estado mismo en su conquista. El 68 es ahora un "fantasma" que regresa como trabajo inmaterial o capitalismo cognitivo. Asimismo, acusa al pensamiento de Foucault de no saber resolver la continuidad entre saber y resistencia (18), ya que cae, según Zizek, en una circularidad en la que el sujeto que resiste a las reglas disciplinarias termina siendo producto de ellas. Este sería, agrega Zizek, un "abrazo mortal recíproco" (18). Informa, eso sí, que en sus últimos libros Foucault habría recapacitado y trazado una nueva genealogía, que esta vez sí puede resistir las técnicas de poder de la modernidad, acudiendo al mundo grecoromano. Sin embargo, no logra el cometido de deshacer el círculo vicioso y termina por romantizar el relato germano-romántico, de modo semejante a Heidegger y Taylor. El sujeto buscado por Foucault es uno capaz de eludir la subjetivación disciplinaria y biopolítica de las tecnologías modernas. 
Según Zizek, lo mismo pasa con el feminismo, el poscolonialismo, los estudios culturales, el posmarxismo, incluida la democracia radical. Estas corrientes serían erróneas porque inventan otras subjetividades, buscan alternativas, sin darse cuenta de que el "subalterno", la "mujer oprimida", la "multitud" o las "sexualidades no heterocentradas" son aliadas del capitalismo global y de la "democracia liberal multiculturalista" (21). El problema que Castro-Gómez perfila en su cartografía del pensamiento de Zizek consiste en hacer ver que la subjetividad es diferente de la subjetivación y que los regímenes de dominación no son históricos. Hasta aquí es apreciable en Zizek una redirección del problema del sujeto y del estatuto del antagonismo, de modo diferente al camino seguido por Deleuze, Foucault y Derrida. La principal crítica a estos autores es haber ignorado la dimensión ontológica de la subjetividad y del antagonismo.

Un detalle significativo es que el historicismo posmoderno denunciado es explicado de modo psicoanalítico por Zizek, que dice que género, raza, clase y orientación sexual existen en función de un "vacío fundamental". Para explicar este vacío recurre a la figura de Descartes, uno de los principales iniciadores de la modernidad desde el punto de vista europeo, pero culpabilizado debido a su paradigma del sujeto-objeto (Heidegger), del ego conquiro de la expansión colonial (Dussel), del cogito asexuado como visión patriarcal masculina, entre otras caracterizaciones del sujeto. Este retorno a Descartes por parte de Zizek no obedece a un deseo de reconfirmar al sujeto soberano; su objetivo es político, ya que busca superar el así llamado "relativismo cultural" o los "particularismos comunitarios" mediante un "universalismo del Capital" (24). De este modo, la refundación del sujeto tiene que ver con una recuperación de la universalidad para combatir por esta vía a la posmodernidad.

En mi opinión, es importante comprender la argumentación de Zizek porque parece representar una amenaza para la filosofía latinoamericana, tanto de la que defiende a la modernidad como de aquella que toma partido por el posmodernismo. Precisamente, la defensa del universalismo equivale prácticamente a la muerte de América Latina como lugar de enunciación y como crítica del eurocentrismo. A lo más, podría salvarse como un "modo de vida" dependiente de la subjetividad abstracta. Sin embargo, la reflexión filosófica Zizek siempre la sostiene en el análisis psicoanalítico. Desde esta clave el autor lee 
a Descartes, en especial cuando indica que la duda que habita en la mente es una "pulsión de muerte", queriendo decir que su estructura le impide alcanzar el objeto de su deseo, porque es ausencia del objeto. Poco a poco Zizek va dando a conocer su convalidación de la mente cartesiana con la psique lacaniana. ¿Adónde se llega con esta lectura? Curiosamente, en este punto Zizek coincide con el argumento de Arendt sobre Descartes, citado antes, aunque ella no es nombrada por el filósofo psicoanalista ni por Castro-Gómez sobre este punto. ¿En qué coinciden? En la certeza de la duda, vale decir, en la falta de un objeto, que Zizek entiende como "división", "hendidura" o "vacío constitutivo" de la conciencia. Esta condición de la conciencia es la que equivale a la subjetividad moderna y a la postulación del "sujeto trascendental". Para aclarar la noción moderna de subjetividad, leída como "falla", "pulsión de muerte" o "negatividad", Zizek recurre al idealismo alemán como una "filosofía insuperable" (28). Desde esta lectura, sería Kant el que saca al sujeto del ser y de la historia y entiende su actividad como "representación" de la realidad. De este modo, el sujeto es un "fantasma" que ni siquiera debe confundirse con el punto de vista humano. Hasta aquí Zizek no dice algo diferente de lo señalado por Heidegger o Arendt sobre la modernidad: la "imagen del mundo" equivale a "representaciones", leídas por Zizek como "ilusiones" o "ideologías". El mundo de la "sustancia" es reemplazado, así, por el mundo del sujeto o por la "subjetividad", coincidiendo en este aspecto con Roig y su afirmación del "discurso del futuro" o "matinal" como mundo "abierto". Con todo, Zizek avanza hasta el último Schelling como "pieza clave" para entender que la libertad es la irrupción de algo no histórico que emerge en un tiempo histórico (40). La libertad es, entonces, "negatividad", palabra que se explica en relación con un mundo siempre incompleto, "ontológicamente agrietado" dice Zizek. De este modo, todo acto de libertad es "traumático" pues rompe con el flujo de lo considerado "normal"; por lo mismo puede considerarse un "acontecimiento" (41). La diferencia con Roig, quien toma a Kant como referente de un discurso moral, es que esta libertad no se rige por un principio normativo. Es un salto al vacío y, por esta razón, se liga a un "mal radical", a un acto de voluntad del que puede derivar la crueldad, el caos o la miseria.

Desde la lectura de Schelling, Zizek se conecta con Hegel, porque este es el filósofo que explica la falta de justificación moral del mundo. 
En esta conexión, el intermediario sigue siendo Lacan. El añadido que pone Hegel a lo señalado por Kant y Schelling es el antagonismo de la negatividad. Castro-Gómez subraya la particularidad de Zizek de alejarse de la lectura teleológica de Hegel y de la resolución de lo negativo en una síntesis superior. Por tanto, en la negación de la negación no hay una superación de los antagonismos del mundo social. Desde esta premisa, el sujeto nunca coincide consigo mismo; en consecuencia, permanece escindido.

A partir de estos argumentos es oportuno preguntarse qué entienden Zizek y Castro-Gómez por “universalidad", ya que lo ineludible de la modernidad y de las transformaciones a las que se aspira es partir de un sujeto que ya no se identifica con su situación actual, como es el caso del esclavo hegeliano. Desde Zizek, la universalidad propuesta nada tendría que ver con el historicismo de la posmodernidad e incluso con el contexto cultural, debido a que el cambio es algo posible fuera de la historia. De allí que la emancipación revolucionaria, por la que se preguntan Zizek y Castro-Gómez, lo que hace es "destruir" un orden positivo. Este acto de "negatividad", como se denomina a la acción revolucionaria, tampoco se puede asociar a la democracia. Tras este modo de pensar a la universalidad en conexión con una negatividad radical, no hay para Zizek un "modo de vida" o particularidad. A partir de estos argumentos afloran las tomas de posición antiparticulturalistas de Zizek, me refiero a su repudio a los movimientos feministas, gays, indígenas o ecologistas, corrientes que se definen en contra del sexismo, racismo, homofobia y colonialismo. Sorprende cuando asevera que estos movimientos son "estilos de vida" capturados por el neoliberalismo (54). Ni siquiera Marx se salva de la crítica al historicismo desarrollada por Zizek, en la medida en que no comprende el "materialismo ontológico" de Hegel. Del mismo modo que confunde el "fetichismo" cuando apunta a las mercancías, en vez de considerar que se trata de la condición humana cuya característica es tener ilusiones, uno de cuyos ejemplos es el dinero (57).

Frente a la caracterización desfondada o insustancial de la condición humana, la "política", como poder constituyente, es un recurso indispensable para "construir un fundamento" (65). En respuesta a Zizek, Castro-Gómez busca desarrollar una teoría emancipatoria de la democracia, eludiendo al sujeto trascendental postulado por Zi- 
zek desde el idealismo trascendental. Por esta vía también defiende a Foucault como un pensador que no elude el antagonismo, pero en su punto de partida reconoce una voluntad que domina hegemonizando, es decir, haciendo que la fuerza vencida acepte la interpretación de la fuerza vencedora para continuar el antagonismo. Castro-Gómez pretende mostrar una simetría entre el sujeto trascendental y el antagonismo como estructura ontológica respecto de Foucault, quien, en compañía de Nietzsche, remite el antagonismo a la experiencia ontológica del cuerpo sumergido en el agonismo de las fuerzas. Pero reconoce que en Foucault falta la diferencia ontológica que permita pensar "lo político", que sí tiene el pensamiento de Claude Lefort cuando reflexiona, ya no desde lo social, sino desde lo ontológico, a diferencia de "la" política que es óntica (253). Desde los argumentos de Zizek, Castro-Gómez admite que lo político no viene de lo social. Al contrario, su proveniencia es simbólica. El sentido común de la sociedad es modificado solo como experiencia de la negatividad. A esta experiencia del antagonismo no se llega desde los esquemas de las ciencias sociales porque ellas no pueden observar lo ontológico del poder. La división social es la base constitutiva o inmanente de lo social sobre cuya lógica se monta la política. De este modo, se llega a que el conflicto es insuperable, está instalado en una matriz simbólica. Con el poder no se puede consensuar, pero sí redistribuirlo socialmente.

Pasemos ahora del antagonismo al universalismo. La pregunta es si este último no es más que la cara del eurocentrismo, es decir, si acaso no corresponde a un espacio cultural concreto, en este caso Europa. Curiosamente, Castro-Gómez va a defender la causa de la universalidad a propósito de la política emancipatoria, a diferencia de lo que hace en sus otros libros. Sin embargo, el camino para eludir la simple particularidad de ciertos feminismos y movimientos identitarios será universalizar la particularidad, esto es, "completar parcialmente el lugar vacío del fundamento" (272). En esta estrategia coincide con Zizek y su sentencia de no renunciar a la universalidad. Aunque no se trata de elegir entre una y otra, sino de aprender el juego político que debe jugarse entre estas dos dimensiones. En este sentido, las identidades subalternas, ya sea de raza, sexual o cultural, no pueden pensarse más que en el contexto de las relaciones de poder que las constituyen como tales. Lo que está en juego, entonces, 
es una posicionalidad más que una identidad. En este punto, CastroGómez repite el argumento utilizado por Judith Butler en su disputa con Zizek, según el cual: "la universalidad no es pronunciable fuera de un lenguaje cultural" (Butler 48).

La pregunta que el mismo Castro-Gómez se hace a propósito de su insistencia en una democracia emancipatoria es por su anacronismo, además porque puede leerse como eurocentrismo. Se sabe que, en nombre de la democracia, muchas veces se hace lo absolutamente contrario, más próximo a la despolitización que a lo político. Por mi parte, me pregunto si esta puede ser una clave para leer el estallido social chileno, dado que, como señala el mismo Castro-Gómez, la vida democrática puede ser un "exceso" que el Estado vigila para castigarlo. En clave pospolítica, se desconfía del hombre democrático como irracional o hedonista. En la perspectiva de Arendt, lo político es lo instituyente, pese a que Castro-Gómez es crítico de esta pensadora de lo político por preferir la revolución norteamericana a la francesa. A juicio del pensador colombiano, es la Revolución Francesa el modelo de toda revolución emancipadora, dando como ejemplo el reclamo de los esclavos haitianos, a partir de los ideales de esta revolución, en contra del colonialismo francés. Este acontecimiento es defendido por Zizek como ejemplo de universalidad política. Pese a su localización europea, para Castro-Gómez lo político tiene el poder de lo constituyente por sobre lo constituido. En el caso de los haitianos, si pudieron reclamar su igualdad es porque se asumieron libres y la entendieron no como" francesa", sino como "democrática".

¿Qué pasa con lo instituido y lo instituyente en Dussel?, filósofo, como se sabe, ligado a los procesos, sociales, éticos y políticos de América Latina. Desde las categorías y criterios que Castro-Gómez toma de Zizek, de Rancière y Lefort, entre otros, Dussel queda muy mal parado, debido a que su política busca primero cubrir las necesidades materiales de la sociedad antes que cubrir un vacío ontológico o establecer lo político en el marco de un litigio. Sin embargo, esta "política de la vida" no es una biopolítica ni tampoco la "zoé" o "nuda vida", caracterizada así por Agamben. Según señala Castro Gómez, en Dussel, lo buscado es un "ser-con-otros" o experiencia común, de acuerdo con la lectura de Heidegger. Con respecto a lo instituido y lo instituyente, advierte en Dussel un temor a lo instituyente. Así pues, su "Filosofía de la Libera- 
ción" queda del lado de una potentia "afirmativa" en el marco de las instituciones privilegiando la potestas (345-346).

Desde su nuevo vínculo con la modernidad y sus categorías, Castro-Gómez defiende de la sociedad civil una autonomía por sobre la institucionalidad del Estado al momento de hablar de democracia, pero eso no quiere decir que no se deba obedecer al mandato del pueblo entregado a los representantes, reservándose el derecho a desobedecer en la sociedad civil. Esta es la gran diferencia con el estatismo de Dussel, entre otros autores.

\section{Ethos barroco como modernidad otra}

Finalizo de modo muy provisorio esta abigarrada exposición sobre la que llamé al inicio de este artículo "la escena problemática" de los comentarios en favor o en contra de la modernidad. Antes de concluir, hago notar los espacios en blanco que necesariamente porta esta exposición sobre la modernidad en América Latina, que podría resultar infinita si quisiera entenderla desde todas sus dimensiones. Sin embargo, es ineludible que desde la pregunta sobre la modernidad no lea a la mayoría de los autores/as que están involucrados/as en este debate. Asimismo, dejo para más adelante la lectura de pensadoras como Rosario Castellanos, María Lugones, Rita Segato, entre otras, debido a que este tema todavía está en etapa de indagación. La visión del feminismo latinoamericano es imprescindible para comprender otro de los hilos de la otredad latinoamericana y su vínculo con la modernidad.

En las últimas líneas quiero señalar que es, quizás, Bolívar Echeverría quien mejor entiende el carácter paradójico de la modernidad en América Latina, cuando considera la vivencia de la modernidad a partir de su tipología de los cuatro "ethos" (realista, romántico, clásico y barroco). Estos cuatro ethos se centran en el aspecto más cultural de la modernidad, aunque referidos al aspecto capitalista. Para Echeverría, fuera de Europa interactúan y se tensionan dos de ellos: el ethos realista y el barroco. La modernidad norteamericana, según vimos, se encuentra regida por el ethos realista de corte puritano, cuya característica es desarrollar una vida funcional: "los trenes parten y llegan a la hora exacta", así como los malls y los bunkers son autosuficientes (Echeverría 2011 32); mientras que la modernidad de América Latina se rige por el ethos barroco que, como otra modalidad del ethos moder- 
no, desarrolla un modo de vivir tensionado, descrito como "estetización exagerada" (Echeverría 2005 13). A mi juicio, esta característica es la que permite denominar a la modernidad latinoamericana "modernidad otra", puesto que, aunque el barroco se desarrolla en Europa, es especialmente "nuestro", dirá Lezama Lima (83). Para el escritor cubano, "lo nuestro" radica en una "tensión" que, en vez de acumular, como en el barroco ibérico, "reúne" o "yuxtapone". Pero, atención, aunque reúna contiene la "ruptura". De modo similar a Lezama Lima, Echeverría sostiene que el barroco es una forma de "resistencia radical", pese a que no es revolucionario (16). Es destacable que, desde lo que aquí se entiende por "resistencia", se aprecie en el ethos barroco el modo en que opera el lenguaje y un estilo de pensamiento que presta nombres a lo que carece de nombre. Por sobre todo, brinda un lugar a lo excluido, aunque se relaciona de modo ambiguo con el centro moderno con el que se tensa (213). Por este y otros motivos, Echeverría toma prestado de Octavio Paz, en especial de su estudio sobre Sor Juana Inés de la Cruz, el término "otra" para referirse a la modernidad en América Latina, aunque la intención de Paz es subrayar que la España "nueva" construida en América era “otra”, en ningún caso "nueva” (182).

Leyendo, tal vez también de modo un poco barroco, desde la otredad que opera en la modernidad pensada y ejercida en América Latina y sin apartarme de la necesaria universalización y futuridad cultural del relato moderno, han aflorado en las lecturas realizadas las tensiones entre dos o más modelos de modernidad. Pero, sobre todo, como característica de la modernidad alternativa pensada en América Latina destaca, a mi juicio, el momento inclusivo del Otro en el pensamiento y en el lenguaje de algunos de los autores leídos, ya como Transmodernidad (Dussel), pensamiento matinal que recomienza (Roig), política instituyente (Castro-Gómez) o forma tensionada de vivir bajo el signo del ethos barroco (Echeverría).

\section{Bibliografía}

Anderson, Perry. Los orígenes de la posmodernidad. Barcelona: Anagrama, 1998.

Arendt, Hannah. La condición humana. Barcelona: Paidós, 2001.

Arpini, Adriana. "Hecho en el exilio. Etapas en el proceso de ampliación metodológica propuesto por Arturo Andrés Roig”. Frag- 
mentos y episodios. Expresiones del pensamiento crítico de América Latina y el Caribe en el siglo XX. Adriana María Arpini (compiladora). Mendoza: Maestría en Estudios Latinoamericanos, Facultad de Ciencias Políticas y Sociales, Universidad de Cuyo, 2017.

Butler, Judith. Contingencia, hegemonía y universalidad. Diálogos contemporáneos en la izquierda. Judith Butler, Ernesto Laclau y Slavoj Zizek, Buenos Aires: Fondo de Cultura Económica, 2004.

Castro-Gómez, Santiago. Crítica de la razón latinoamericana. Barcelona: Puvill Libros S.A., 1996

Castro-Gómez, Santiago. La hybris del punto cero, Ciencia, raza e ilustración en la Nueva Granada (1750-1816). Bogotá, Editorial Pontificia Universidad Javeriana, 2010.

Castro-Gómez, Santiago. Revoluciones sin sujeto. Slavoj Zizek y la crítica del historicismo posmoderno. México: Akal, 2015.

Chiampi, Irlemar. Barroco y modernidad. México: Fondo de Cultura Económica, 2000.

Contardi, Laura Aldana. "La filosofía latinoamericana como filosofía del sujeto en la propuesta filosófica de Arturo Andrés Roig", Tesis de Doctorado, Facultad de Filosofía y Letras, Mendoza: Universidad de Cuyo, 2015.

Dussel, Enrique. 1492. El encubrimiento del Otro. Hacia el origen del mito de la modernidad, Madrid: Editorial Nueva Utopía, 1992.

Dussel, Enrique. La ética de la liberación ante el desafío de Apel, Taylor y Vattimo con respuesta crítica inédita de K.O. Apel. Argentina: Biblioteca virtual del Consejo Latinoamericano de Ciencias Sociales (CLACSO), 1998.

Dussel, Enrique. Materiales para una política de la liberación. México: Universidad Autónoma de Nuevo León, 2007.

Dussel, Enrique. En búsqueda del sentido. Sobre el origen y desarrollo de una Filosofía de la Liberación. Buenos Aires: Editorial Las cuarenta, 2018.

Echeverría, Bolívar. "La modernidad americana. Claves para su comprensión". La americanización de la modernidad, Bolívar Echeverría (compilador). México: Ediciones Era, 2011.

Echeverría, Bolívar. La modernidad de lo barroco. México: Ediciones Era, 2005. 
Giusti, Miguel (1989), “Hegel ante la modernidad", Areté. Revista de Filosofía 1 (1), Departamento de Humanidades Pontifica Universidad Católica del Perú.

Habermas, Jürgen. El discurso filosófico de la modernidad. Madrid: Taurus, 1993.

Heidegger, Martín. Caminos del bosque. Madrid: Alianza Editorial, 1998. Jameson, Fredric. Teoría de la postmodernidad. Madrid: Trotta, 1998.

Lezama Lima, José. La expresión americana. México: Fondo de Cultura Económica, 1993.

Lyotard, Jean- François. La condición postmoderna. Madrid: Cátedra, 1989.

Mignolo, Walter. Desobediencia epistémica. Retórica de la modernidad, lógica de la colonialidad y gramática de la descolonialidad. Buenos Aires: Ediciones del Signo: 2017.

Morandé, Pedro. Cultura y modernización en América Latina. Ensayo sociológico acerca de la crisis del desarrollismo y de su superación. Santiago de Chile: Instituto de Sociología, Universidad Católica, 1984.

Morse, Richard. El espejo de Próspero. Un estudio de la dialéctica del nuevo mundo. México: Siglo Veintiuno, 1999.

Quijano, Aníbal. Modernidad, identidad y utopía en América Latina. Lima: Ediciones Apartado, 1988.

Rama, Ángel. La ciudad letrada. Santiago de Chile: Tajamares Editores, 2004.

Roig, Arturo Andrés. Ética de poder y moral de la emergencia. Respuesta a la crisis moral de nuestro tiempo. Mendoza: EDIUNC, Editorial de la Universidad de Cuyo, 2002.

Roig, Arturo Andrés. Teoría y crítica del pensamiento latinoamericano. Buenos Aires: Una ventana, 2009.

Roig, Arturo Andrés. Rostro y filosofía de Nuestra América. Buenos Aires: Una ventana, 2011.

Salazar Bondy, Augusto. ¿Existe una filosofía de Nuestra América? Buenos Aires: Siglo Veintiuno, 1968.

Sánchez, Cecilia. El conflicto entre la letra y la escritura. Legalidades/ contralegalidades de la comunidad de la lengua en HispanoAmérica y América-Latina. Santiago de Chile: Fondo de Cultura Económica, 2013. 
Taylor, Charles. La ética de la autenticidad. Barcelona: Paidós, 1994.

Vattimo, Gianni. El fin de la modernidad. Nihilismo y hermenéutica en la cultura posmoderna. Barcelona: Gedisa, 1998.

Zea, Leopoldo. La esencia de lo americano. Buenos Aires: Pleamar, 1971. 